\title{
Access Routes to BODY PART Multiword Expressions in the 'Big Five' MELDs: Use of Hyperlinks
}

Sylwia Wojciechowska, Faculty of English, Adam Mickiewicz University, Poznań, Poland (swojciechowska@wa.amu.edu.pl)

\begin{abstract}
The treatment of multiword expressions (MWEs) in dictionaries has not received much attention in metalexicography, although the significant role of phraseology has been stressed since the advent of corpus linguistics. The paper aims to analyse the lexicographic representation of semantically related MWEs, containing body part names. The study focuses on access routes to these MWEs in the 'Big Five' monolingual English learners' dictionaries online (MELDs). It investigates the presence and positions of hyperlinked MWEs on the page of the body part headword in order to find out if they depend on a given MWE or are dictionary-specific. Double or multiple hyperlinks to the same MWE are frequently found within a single body part entry, and the variety of access routes is evaluated with a view to offering a more homogeneous presentation of hyperlinked related MWEs.
\end{abstract}

Keywords: MONOLINGUAL ENGLISH LEARNERS' DICTIONARIES, MULTIWORD EXPRESSIONS, METONYMY, COGNITIVE LEXICOGRAPHY, ACCESS ROUTES, ONLINE DICTIONARIES

Opsomming: Toegangsroetes na meerwoordige LIGGAAMSDEEL-uitdrukkings in die 'Groot Vyf' MELDs: Die gebruik van hiperskakels. Alhoewel die beduidende rol van fraseologie sedert die ontstaan van die korpuslinguistiek beklemtoon is, het die hantering van meerwoordige uitdrukkings (MWU's) in woordeboeke nog nie baie aandag in die metaleksikografie geniet nie. Hierdie artikel het die analise van die leksikografiese voorstelling van semanties verwante MWU's, wat die name van liggaamsdele bevat, ten doel. Die navorsing fokus op toegangsroetes na hierdie MWU's in die "Groot Vyf" aanlyn eentalige Engelse aanleerderswoordeboeke (MELDs). Die voorkoms en ligging van aaneengeskakelde MWU's op die bladsy waarop die liggaamsdeel-trefwoord voorkom, word ondersoek om sodoende te bepaal of hulle afhanklik is van ' $n$ gegewe MWU en of hulle woordeboekspesifiek is. Dubbel- of veelvoudige hiperskakels van dieselfde MWU kom dikwels binne 'n enkele liggaamsdeel-inskrywing voor, en die verskillende toegangsroetes word met die oog op die aanbied van 'n meer homogene voorstelling van aaneengeskakelde verwante MWU's geëvalueer.

Sleutelwoorde: EENTALIGE ENGELSE AANLEERDERSWOORDEBOEKE, MEERWOORDIGE UITDRUKKINGS, METONOMIE, KOGNITIEWE LEKSIKOGRAFIE, TOEGANGSROETES, AANLYN WOORDEBOEKE 


\section{Background}

Already in the first half of the 20th century, the authors of the first English pedagogical dictionaries, Harold Palmer and A.S. Hornby, acknowledged the role of phraseology in learning a foreign language (Palmer 1933). However, the importance of phraseology began to be widely recognised with the emergence of corpus linguistics and the seminal works of John Sinclair $(1987,1991)$. Since that time (meta)lexicographers have stressed the role of multiword expressions (henceforth MWEs) in determining meaning, for example, Cowie (1998), Moon (1998) and Hanks (2013). This, however, has not translated into studies of the representation of MWEs in dictionaries, and the status of MWEs in lexicography still remains unsettled.

One reason behind neglecting this issue in metalexicography is lack of consensus concerning MWEs terminology. While proposing her own typology of fixed expressions and idioms, Moon (1998: 19-20) observes that there is no generally agreed set of categories in the literature subsumed under MWEs, and clear classifications are impossible. Collocations, idioms, phrases, similes, metaphors and sayings overlap, and it is often hard to assign a MWE to a single category. Another reason is 'the privileged status that the (orthographic) word has traditionally enjoyed in lexicography' (Lew 2012: 349). This is not surprising due to the variable lexical and structural fixedness of MWEs as shown by corpus-based research (e.g. Moon 1998, Fellbaum 2007, Stathi 2007). The unstable nature of MWEs would be an obstacle if they were to serve as the building blocks of the dictionary macrostructure. Moreover, as Lew (2012) notes, dictionary users tend to look up a single word, either not realising that they are dealing with a MWE or merely because this is, or rather 'was' thanks to search interface enhancement in online dictionaries, a familiar strategy. ${ }^{1}$ Advanced dictionary users will usually recognise an item as a MWE, but they may not be sure as to the scope of a MWE. However, the fact that their search strings will vary from the canonical form included in the dictionary does not constitute a problem any longer owing to the partial matching functionality in many online dictionaries.

The result of all this is inconsistent treatment of MWEs in many printed dictionaries, as observed by Oppentocht and Schutz (2003: 218): '[t]hese can often be found under more than one entry, in different forms, and even with different explanations'. At the same time, the authors envisage that such anomalies will not occur in electronic dictionaries due to the use of proper computational tools. The current study does not support this claim, as it shows duplication or multiplication of information and cases of inconsistent treatment concerning MWEs in present-day monolingual English learners' dictionaries (henceforth MELDs) online.

\section{Study}

\subsection{Aims}

The present study deals with the lexicographic representation of MWEs in 
MELDs online, focusing on access routes. It needs to be stressed that the analysis is not concerned with the search route or path a user follows to look up the target item, but with the access structure that determines the search route. ${ }^{2}$ The study aims to examine access routes to semantically related MWEs, containing body part names.

The following research questions are posed:

(1) Are idioms defined within entries for certain body part names or in separate hyperlinked entries?

(2) Where are the definitions of MWEs or hyperlinks to them located on the page of the body part headword?

(3) Is the use of hyperlinks dictionary-specific or item-specific?

(4) Do the dictionaries offer a consistent approach?

It is assumed that taking into account an extensive use of hyperlinks in electronic lexicography, dictionaries will exploit this lexicographic device as a way of cross-referencing, and hence facilitate access to related lexical items.

\subsection{Data and materials}

MWEs with body parts names have been chosen for the present study because they constitute a fairly homogenous group, related by means of metonymic motivation, and are therefore expected to be treated in a fairly consistent way. In fact, these expressions often exhibit a mixed motivation where metonymy is intertwined with metaphor, taking the form of 'metaphtonymy' (Goossens 1990). ${ }^{3}$ In cognitive linguistic literature the notion of idiom motivation is widely acknowledged (e.g. Gibbs 1993, Geeraerts 2002, Dobrovol'skij and Piirainen 2005, Langlotz 2006). Idioms are no longer viewed as long words, but as constructions that have their internal syntactic and semantic structure. Metonymic motivation can be illustrated by be all ears in the current study, where the part of the body stands for the action of listening (BODY PART FOR ACTION metonymy). The interplay of metaphor and metonymy is represented in the examined sample by, for example, bite the hand that feeds you. The decomposable nature of this idiom is reflected by two underlying metaphors and one metonymy: harming is understood in terms of attacking someone physically (HARMING IS ATTACKING metaphor), helping in terms of feeding (HELPING IS FEEDING metaphor), and the body part stands for a person (BODY PART FOR PERSON metonymy).

The study analyses access routes to MWEs with three body part names in their nominal forms: ear, hand and shoulder in the 'Big Five' MELDs online: Cambridge Advanced Learner's Dictionary (CALD), COBUILD Advanced English Dictionary (COBUILD), Longman Dictionary of Contemporary English (LDOCE), Macmillan English Dictionary Online (MEDO) and Oxford Advanced Learner's Dictionary (OALD). ${ }^{4}$ It needs to be added that dictionaries aggregated on the page of a certain dictionary are also taken into account provided they are aimed at advanced learners of English and are not American English versions. ${ }^{5}$ Thus, hyperlinks to 
the following dictionaries are included in the study: in CALD, to Cambridge Academic Content Dictionary (CACD), and Cambridge Business English Dictionary (CBED); and in COBUILD, to Easy Learning Idioms Dictionary (ELID). The other three dictionaries do not contain hyperlinks to aggregated dictionaries. ${ }^{6}$

The study has provided representative results, so there has been no need to extend the sample by incorporating MWEs with other body part names. While selecting items for analysis, the term MWE has been applied in the general sense, namely all types of composite expressions have been chosen, more and less fixed: collocations, idioms, compound nouns, phrases and sayings. The examined material comprises all ear, hand and shoulder MWEs covered in the 'Big Five', but is then reduced to include only the ones present in all the five MELDs. MWEs have been excluded from the sample if body part names appear in attributive position, for example, hand luggage; if MWEs are based only on metaphor, not metonymy, for example, minute hand; and if they have a literal meaning, for example, shrug your shoulders, have your ears pierced. Slight differences in canonical forms are not relevant for the study, for example, make/lose money hand over fist vs. the truncated form hand over fist, or be caught with your fingers/hand in the till vs. have your hands/fingers in the till. These forms are treated as variants of the same MWE. The total number of body part MWEs analysed and tagged is 106 in CALD, 103 in COBUILD, 99 in LDOCE, 107 in MEDO, and 142 in OALD.

\subsection{Procedure}

The analysis proceeds in a few steps and the relevant data are entered into separate Excel files created for each of the five MELDs. First, ear, hand and shoulder MWEs are tagged as being defined on the page of the body part entry, or hyperlinked from it to a separate entry. Next, if the former is the case, it is checked whether a given MWEs is presented under a separate sense or covered at the bottom of the entry in a dedicated idioms or phrases box or section. If the latter is the status quo, the position of the hyperlink is examined: as a separate sense, in the idioms or phrases box or section, or in a separate panel with more results. The last of these options, a search panel is a solution adopted in current online dictionaries to help the user with potential target items including the search word or string. This is a form of step-wise access available when the search item matches more than a single lemma or is part of a MWE (for further discussion see Lew 2012). In CALD such a search panel is named More meanings of, henceforth referred to as MM; in COBUILD, Related terms of (RT); in LDOCE, More results (MR); in MEDO, Other entries for $(\mathrm{OE})^{7}$; and in OALD, Other results (OR). Finally, it is investigated how consistent the dictionaries are in terms of access routes to body part MWEs, and how similar their approaches are when compared to one another.

While analysing access routes to body part MWEs, attention is also paid to reflecting the semantic relations which hold between some expressions. Evalua- 
tion is carried out from the perspective of cognitive linguistics. Adopting the cognitive approach in this paper is supported by the fact that increasing numbers of (meta)lexicographers and cognitive linguists recognise the advantages of its application in lexicography, for example, Van der Meer (1999), Moon (2004), Geeraerts (2007), Adamska-Sałaciak (2008), Atkins and Rundell (2008), Kövecses and Csábi (2014) and Ostermann (2015), the last of whom in fact coined the term cognitive lexicography. Moreover, the cognitive perspective is also in line with the current tendency in pedagogical lexicography towards explicating figurative language usage. Boers and Lindstromberg (2006), for instance, prove in their studies that new lexical items, including idiomatic expressions, are learned and recalled more effectively when their motivation is explained.

\section{Results}

\subsection{Defined or hyperlinked}

The results of the study demonstrate that in four out of five dictionaries under scrutiny, body part MWEs are hyperlinked in the overwhelming majority of cases rather than defined in the entry for the body part name. The proportions of hyperlinked MWEs are equal or close to equal in CALD, COBUILD, LDOCE and MEDO: $95 \%, 92 \%, 95 \%$ and $92 \%$ respectively. OALD turns out to offer a completely opposite approach with merely $8 \%$ hyperlinked body part MWEs (see Figure 1). In this dictionary, the prevailing treatment is defining MWEs in an alphabetically arranged Idioms box at the bottom of the entry: 128 MWEs out of 142 under examination (90\%). In LDOCE, a similar box is found, with collocations instead of idioms. Definitions are also provided without recourse to hyperlinks. However, all the expressions included in these Collocations boxes have literal meanings, and as such are not taken into account in the study, for example, wave your hand and hunch your shoulders.

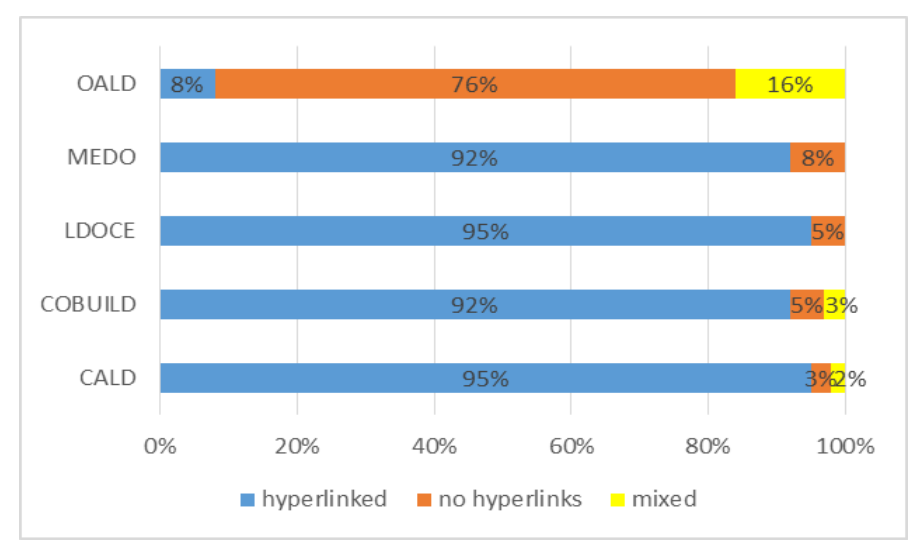

Figure 1: The proportions of hyperlinked MWEs in the 'Big Five' 
What is surprising from a semantic perspective, five body part MWEs are defined twice in the Idioms box in OALD. Among them is win something hands down, which is broken into separate MWEs, hands down and win (something) hands down, the former featuring win hands down in an example sentence (see Figure 2). As MWEs are alphabetically ordered in the Idioms box, the two idioms are further separated from each other by other MWEs which come in between. Such a split is redundant and also creates semantic distance between the two related expressions, which goes against the cognitive approach. The other related MWEs which should not be split in the Idioms box in OALD are in somebody's capable, safe, etc. hands and in safe hands/in the safe hands of somebody; somebody's ears are burning and feel your ears burning; off your hands and on your hands; and (at) first hand and (at) second, third, etc. hand. These pairs are clearly variants of the same MWEs, and the user should see the connection between them.

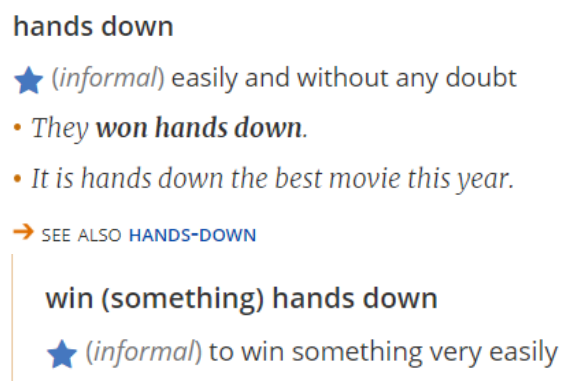

Figure 2: Double access to win something hands down in the Idioms box in OALD

As Figure 1 shows, in three dictionaries, CALD, COBUILD and OALD, mixed treatment is found. This happens when there are double or multiple routes of accessing a given MWE from the page of the headword, with and without hyperlinks. Such cases make up a small proportion of the investigated items, the highest observed in OALD, $16 \%$. For instance, in OALD give somebody the cold shoulder is defined in the Idioms box, and also hyperlinked from the OR right-hand panel, both from the All matches and Idioms sections.

As far as defining body part MWEs under separate senses is concerned, the numbers for all the dictionaries are very low, and include also MWEs that feature only in example sentences under a specific sense (see Figure 3 for MWEs presented under separate senses). In CALD there are 5 out of 106 such cases; in COBUILD, 8 out of 103; in LDOCE, 5 out of 99; in MEDO, 9 out of 107; and in OALD, 4 out of 142. In two dictionaries, CALD and COBUILD, some of these occurrences exhibit the above-mentioned mixed treatment, combining definitions or examples under separate senses on the page of the headword with hyperlinked MWEs. Such cases may result in breaking semantic links between related items. A case in point is separating the expression give some- 
body a hand from lend somebody $a$ hand in COBUILD, with the former featuring in example sentences under sense 4 ('help' meaning), and the latter detached from it and hyperlinked under sense 36. It is worth noting that in the other four MELDs the two variant forms of the same expression are nested under the same sense.

\subsection{Positions of hyperlinked body part MWEs}

3.2.1 Dictionary-specific locations. As has been shown in 3.1, very few of the analysed MWEs are defined in the body part entry, the majority of them being hyperlinked, with the exception of OALD. This section focuses on the different locations of hyperlinks within the entry in each of the 'Big Five'.

2 [SINGULAR] the ability to hear and judge sounds She has a very good ear for music.

T) Synonyms and related words

The ear and hearing: anvil, (as) deaf as a post, audio-

\section{Explore Thesaurus}

3 [COUNTABle] the part at the top of a plant such as wheat that contains the grain

ears of wheat

Synonyms and related words

Parts of plants: aerial root, anther, beanstalk.

Explore Thesaurus

\section{From our crowdsourced Open Dictionary}

4 listen with half an ear to not listen carefully

I was listening to the music with half an ear as I repaired the car.

Submitted by Emran Khoshrouye Ghiasi from Iran, Islamic Republic of on $16 / 12 / 2018$

Figure 3: MWEs with ear defined as a separate sense (sense 4) and featuring in an example sentence (sense 2) in MEDO 
In CALD, the prevailing location is the MM right-hand panel, listing $95 \%$ of the examined MWEs (see Figure 4). Body part MWEs are also hyperlinked from the Idioms box at the end of the entry, $38 \%$, and there is one case of a hyperlink from a separate sense. This single MWE is the compound farmhand (1\%), which is cross-referenced from the sense of 'a worker'. It needs to be added that these percentages do not make up together 100\% because the same idiom is sometimes hyperlinked twice or more in different places in the entry. This duplication or multiplication of hyperlinks is also observed in the other dictionaries, and will be discussed in 3.2.3.

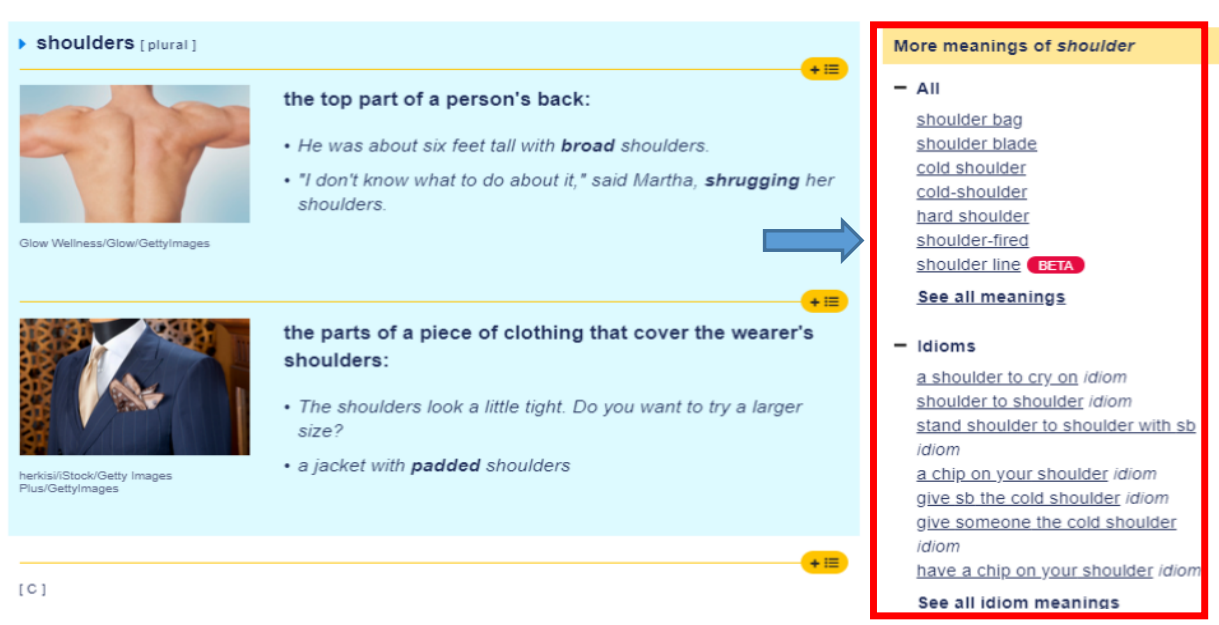

Figure 4: The MM panel on the page of the headword shoulder in CALD

COBUILD also assigns hyperlinked body part MWEs to three different locations, two of them being equally frequent: the More idioms (MI) section at the bottom of the page after entries from the aggregated dictionaries, and separate numbered senses, $58 \%$ and $57 \%$ respectively. The third position is also at the bottom of the page in the RT section, $21 \%$.

Separate hyperlinked numbered senses are also the most frequent in LDOCE, constituting $65 \%$ of all the examined MWEs. The other two positions are: the MR right-hand panel and hyperlinks grouped at the bottom of the entry before the Collocations box, $36 \%$ and $18 \%$ respectively.

MEDO takes a completely different strategy, and does not place hyperlinks under separate numbered senses except one occurrence, show your hand, hyperlinked from the sense of 'advantages in a situation'. Instead, the dominant location for hyperlinked MWEs in MEDO is the OE right-hand panel, $65 \%$, followed by the Phrases section at the end of the entry, $47 \%$. There are also sin- 
gle occurrences of hyperlinked MWEs in the See also section at the very bottom of the entry, making up a mere $10 \%$.

As has already been said in 3.1, in OALD the bulk of body part MWEs are not hyperlinked, but defined in the Idioms box (90\%). Hyperlinks are only used in the OR right-hand panel, constituting $21 \%$ of the investigated expressions, and very rarely under separate senses, $3,5 \%$ or under the See also cross-references $^{8}$ at the bottom of the entry before the Idioms box, $1 \%$. It is observed that the last two locations contain hyperlinks to one specific category of MWEs, body part compound nouns, for example, chargehand, farmhand, deckhand, dab hand, glue ear and hard shoulder. ${ }^{9}$

The above findings indicate that the examined dictionaries offer relatively consistent and dictionary-specific access routes to hand, shoulder and ear MWEs in terms of the presence of hyperlinks and their position on the page of the headword. At the same time, some similarities emerge between the dictionaries. Hyperlinks from separate numbered senses predominate in LDOCE and COBUILD. Idioms or Phrases sections subsuming hyperlinked MWEs are the distinguishing feature of COBUILD and MEDO, not hyperlinked ones, of OALD. It should be pointed out here that in the Idioms section in COBUILD (MI), MWEs are hyperlinked to their entries in the aggregated dictionary ELID. Finally, search panels with more results are found in all the dictionaries, and are placed to the right towards the top of the entry, with the exception of COBUILD, in which they are located at the very bottom of the entry. Here, it should be noted that on mobile phones, the search panels appear at the bottom of the screen, after the text of the main entry including Idioms or Collocations boxes or sections. The only exception is MEDO, with the OE search panel placed at the very top of the entry. Search panels constitute the preferred location for hyperlinked body part MWEs in CALD and MEDO.

Despite the lack of a clear typology of MWEs in literature, some classification is attempted in the examined MELDs, at least to distinguish idioms from other MWEs, as there is an Idioms section or box in CALD and OALD. In MEDO it is called Phrases section, and in COBUILD, More idioms (MI), suggesting that it only adds to the list of hyperlinked MWEs placed under separate numbered senses. Moreover, in some of the dictionaries, search panels with more results are divided into All matches and Idioms sections. In both CALD and OALD, the latter selects only idiomatic expressions from the All matches section. In LDOCE and COBUILD no distinction is made between idioms and other expressions in the search panels, whereas in MEDO, although the panel is not divided either, idioms are distinguished from the other lexemes such as compound nouns (e.g. old hand, ear candy) by the label PHRASE assigned to them.

It is, nonetheless, hard to explain the reasoning behind establishing the See also section for just a few hyperlinked MWEs, as is the case in LDOCE, MEDO and OALD. In particular, it is puzzling in MEDO, where it is located at the very bottom of the entry, after the Phrases section, and contains hyperlinks to expressions that could well be added the Phrases section, and are already in- 
cluded in the OE search panel, for example, cold shoulder or the ones that should be added to either or both of the above-mentioned sections, for example, all hands on deck. In LDOCE such additional hyperlinks are grouped after the numbered senses, although they could be added to the list of the numbered hyperlinked senses, the only downside being that it might get too long then. Finally, in OALD, the presence of the See also hyperlinks is perhaps more justifiable, because, as has already been mentioned, they are cross-references to one category of MWEs, body part compound nouns.

3.2.2 The hyperlinked pages. In the examined MELDs except OALD, the crossreferenced body part MWE tends to be the headword of the hyperlinked entry. In OALD, 23 out of 37 hyperlinked MWEs take the user from the OR panel to the Idioms box under a different headword, another content word from the target MWE. In all the cases, the page scrolls down to the searched MWE. For instance, for bite the hand that feeds you the hyperlinked page is the entry for bite (verb), and the page scrolls down to the target idiom in the Idioms box, and for give somebody the cold shoulder, the cross-referenced page goes down to the definition of the idiom in the Idioms box in the entry for cold (adjective).

Automatic scrolling to the target hyperlinked item has, however, not been found in COBUILD. The idiom hand in hand is cross-referenced from two consecutive numbered senses under the headword hand, sense 24 and sense 25 (see Figure 5), and the hyperlinked page contains two entries, the first for the literal sense and the second for the figurative one. The problem is that both cross-references go to the top of the hyperlinked page, where the literal sense is covered, and the user may overlook the other sense, the figurative one, if they do not scroll down the screen (see Figure 6).

22. See get one's hands on sth

23. See hand in glove
24. See hand in hand
25. See hand in hand
26. See have a hand in sth
27. See a heavy hand

Figure 5: Hyperlinked senses of hand in hand in COBUILD 


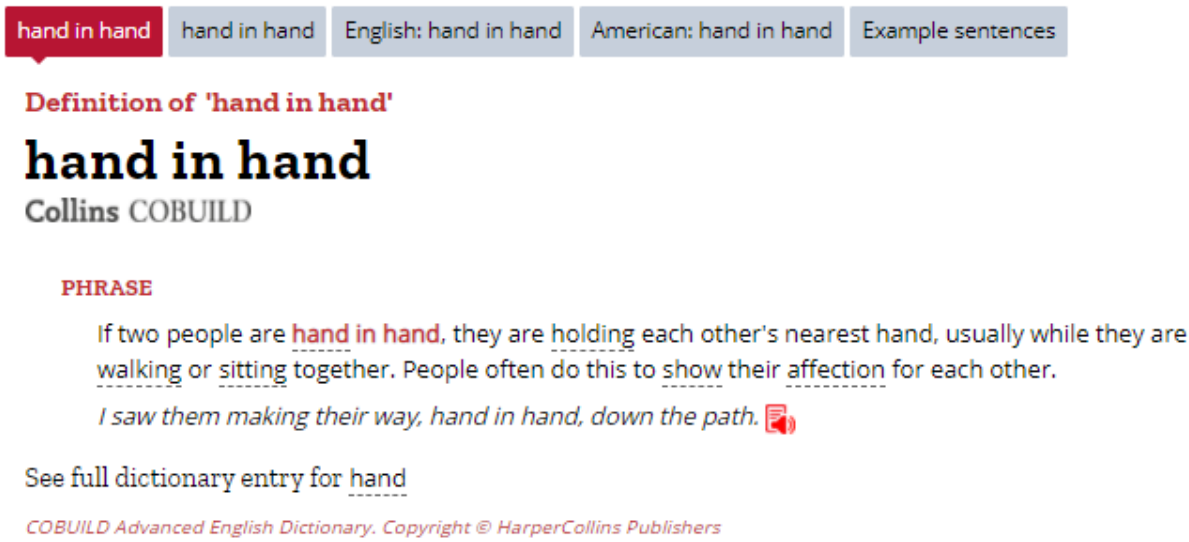

Collins COBUILD

\section{hand in hand}

Collins COBUILD

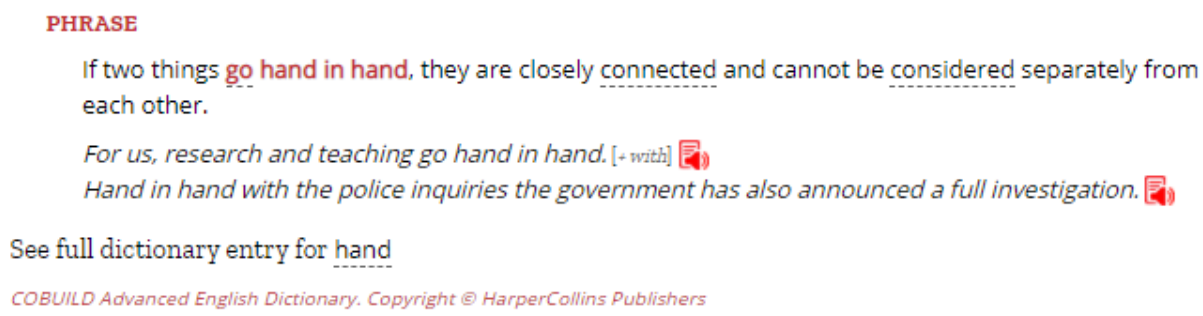

Figure 6: Page hyperlinked from hand in hand in senses 24 and 25 in COBUILD

The same treatment is noticed for the idiom shoulder to shoulder, hyperlinked from senses 12 and 13. Similarly, the prepositional phrase in hand is hyperlinked as many as four times from four consecutive senses: 30, 31, 32 and 33, with no automatic scrolling to the second, third or fourth entries representing different meanings of the expression. This practice does not facilitate the lookup process.

While examining access routes, some erroneous hyperlinks with no relevant content have been found. In CALD, there are 12 instances of hand MWEs hyperlinked from the MM panel to the top of the entry for hand (n) instead of being hyperlinked to an entry with the target MWE as the headword, for example, at hand, and some other prepositional phrases with hand such as by hand, in hand, on hand, to hand, and also hand in hand, the job/matter in hand, put your hand in your pocket. Coincidentally, these erroneous hyperlinks to all of them except the last one appear on the third page of the MM panel; to the last one, 
on the fourth page. In fact, the other hyperlinks with the above-mentioned MWEs, if present, work fine in CALD.

3.2.3 Duplication or multiplication of hyperlinks. As has already been stated, it often happens that there are two or more ways of accessing the examined MWEs within a single body part entry. The study aims to find out (1) how many items are accessed both from the main entry (henceforth ME) and the search panel (Scenario 1), and (2) how many are hyperlinked twice or more within the search panel (Scenario 2). In Scenario 1, access from ME can take the form of a separate sense (the MWE being defined, hyperlinked or provided in an example sentence), or a hyperlink or definition in the Idioms or Phrases box or section. In Scenario 2, the focus is only on the presence of double or multiple hyperlinks within the search panel, no matter if a given expression is at the same time accessed from ME or not.

The highest percentage of double or multiple access routes is found in CALD. A staggering $85 \%$ of the body part MWEs are cross-referenced at least twice within the MM search panel (Scenario 2). Moreover, there is double access from ME and the MM panel, constituting 39\% (Scenario 1). The abundance of hyperlinks results from aggregating two other dictionaries apart from CALD into the Cambridge Dictionary online: CACD and CBED. Double or multiple access to body part MWEs is also observed in the other dictionaries. In COBUILD, 35\% of the examined MWEs are defined or hyperlinked in ME as well as being hyperlinked from the MI and/or RT sections (Scenario 1), whereas $11 \%$ of them are cross-referenced from both MI and RT (Scenario 2). The latter case is exemplified in Figure 7, where (give someone) the cold shoulder is hyperlinked from both MI and RT. The MI section is treated here separately from $\mathrm{ME}$, because, as has already been mentioned, it is situated far from it, at the bottom of the page after entries from the aggregated dictionaries. Moreover, it contains hyperlinks to entries from one of the aggregated dictionaries, ELID (see Figure 8). In LDOCE, only one of the above scenarios is found, Scenario 1: $24 \%$ of the body part MWEs are hyperlinked from ME and the MR search panel. In MEDO: $32 \%$ are hyperlinked from ME and the OE search panel (Scenario 1), and a mere $2 \%$ have double hyperlinks within OE (Scenario 2). Finally, duplication or multiplication of hyperlinks is the least frequent in OALD due to the lowest number of hyperlinks: $19 \%$ of the MWEs receive double access from ME and the OR panel (Scenario 1); $5 \%$ are hyperlinked twice within OR (Scenario 2). 
More idioms containing

\section{shoulder}

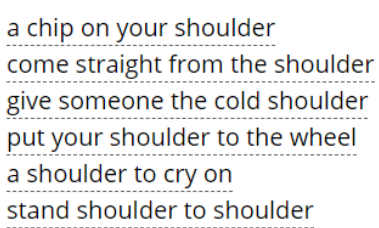

a chip on your shoulder come straight from the shoulder give someone the cold shoulder put your shoulder to the wheel a shoulder to cry on stand shoulder to shoulder

\section{Related terms of}

\section{shoulder}

\author{
cold shoulder \\ hard shoulder \\ shoulder arms \\ shoulder-bag \\ shoulder-high
}

View more related words

Figure 7: Double hyperlinks to (give someone) the cold shoulder from the search panel in COBUILD

\section{give someone the cold shoulder}

to deliberately ignore someone

He gave me the cold shoulder at the party; he didn't talk to me at all.

Easy Learning Idioms Dictionary. Copyright @ HarperCollins Publishers

Figure 8: The hyperlinked entry for give someone the cold shoulder in ELID

The highest number of hyperlinks is found in CALD for (on the one hand ...) on the other hand, which is cross-referenced six times in the MM panel: three times under All meanings and three times under Idioms. As has been observed in 3.2.1, the Idioms section in the search panel features the idioms included in the All meanings section, so it may as well be claimed that the expression is hyperlinked three times in the MM panel. Moreover, it is cross-referenced from the Idioms box at the bottom of ME (see Figure 9). Cross-referencing from the MM panel apart from the hyperlink in ME is fine, and should not be viewed as redundant, as the panel's main function is facilitating access to the searched item (see section 2.3). It is, however, worth noting that there are slightly different forms of this idiom in the hyperlinks from the MM panel (see Figure 10). As has been pointed out in 2.2, they are treated in this study as variants of the same MWE. Under All meanings in the MM panel, there is one cross-reference to on the one hand ... on the other hand in CALD, and cross-references to two variant forms in CACD on the one hand but on the other hand and on the other hand. In the Idioms box at the bottom of $\mathrm{ME}$, there is a hyperlink to the form on the one hand ... on the other hand. 


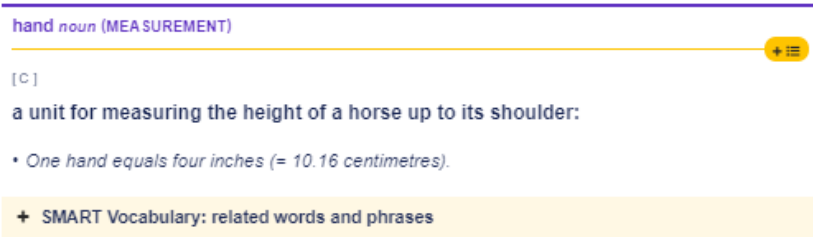

+ SMART Vocabulary: related words and phrases

\begin{tabular}{|c|c|}
\hline \multicolumn{2}{|l|}{ Idioms } \\
\hline at hand & at the hands of $s b$ \\
\hline a game in hand & get/ay/put your hands on sb \\
\hline get/laylput your hands on sth & go hand in hand with sth \\
\hline hand in glove & hand in hand \\
\hline hand over fist & hand to hand \\
\hline \multicolumn{2}{|l|}{ - More idioms } \\
\hline sb's hands are tied & have your hands full \\
\hline have sth in hand & have sth on your hands \\
\hline hold/put your hands up & in hand \\
\hline the job/matter in hand & keep your hand in \\
\hline keep a firm hand on sth & live (from) hand to mouth \\
\hline on hand & on the one hand .... on the other hand \\
\hline out of hand & put your hand in your pocket \\
\hline a safe pair of hands & take sb/sth in hand \\
\hline
\end{tabular}

Figure 9: Hyperlink to on the one hand ... on the other hand from the Idioms box in CALD

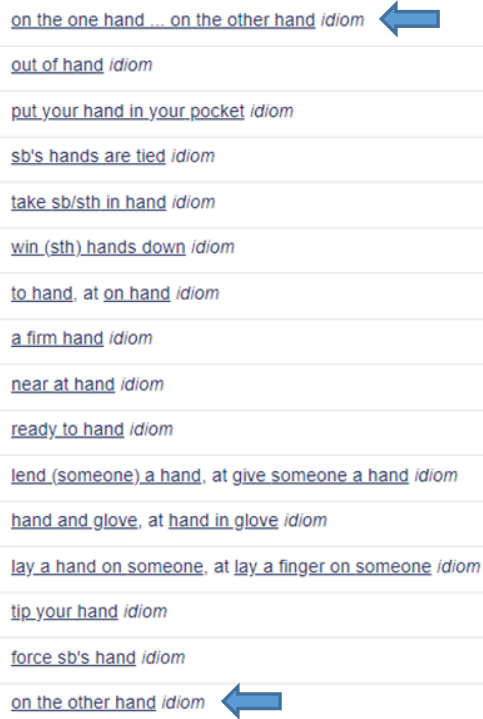

Figure 10: Extract from the MM panel in CALD with hyperlinks to variant forms of the idiom (on the one hand ...) on the other hand 
One may wonder if all these hyperlinks take the user to the same entry, with an identical definition and the same example sentences. As it is rightly assumed, this is the case for the hyperlinked entries within CALD, but may not necessarily be so for the ones from CACD, especially as the canonical forms slightly differ. Indeed, as Figure 11 demonstrates, in CACD, the definition and example sentences provided in the cross-referenced entries for on the one hand but on the other hand and the truncated form on the other hand are different.

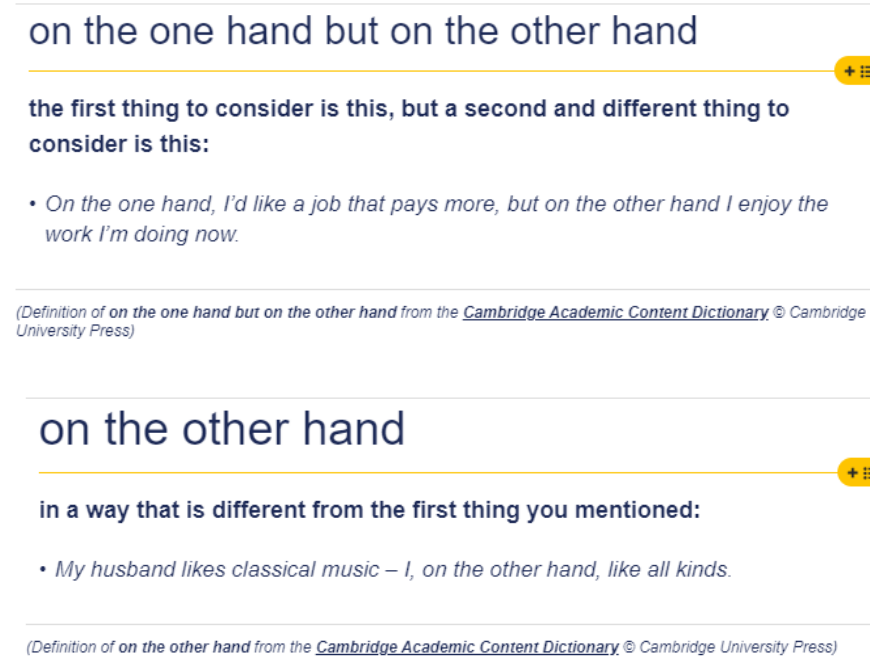

\section{on the other hand}

in a way that is different from the first thing you mentioned:

- My husband likes classical music - I, on the other hand, like all kinds

(Definition of on the other hand from the Cambridge Academic Content Dictionary @ Cambridge University Press)

Figure 11: Two different hyperlinked entries for two variant forms in CACD

In fact, in the first hyperlinked entry from CACD quoted above, the example sentence is the same as in the cross-referenced entry in CALD. Definitions are, however, different in all the three hyperlinked entries, including the metalinguistic definition in CALD: 'used when you are comparing two different facts or two opposite ways of thinking about a situation'. This multiplication of hyperlinks with differing content appears to be redundant and also misleading for the user, who may think that these are distinct expressions, not just variants of the same form. It is justifiable if differing hyperlinks come from two aggregated dictionaries, like here CALD and CACD, but should be viewed as examples of redundancy and inconsistency if they are from the same dictionary, here from CACD. It is also suggested that there should be one canonical form with the first part of the idiom given in brackets (on the one hand ...) on the other hand.

Two other of the dictionaries under scrutiny, COBUILD and MEDO, also provide more than one hyperlinked entry for this MWE. In COBUILD on the one hand is hyperlinked under sense 41 and on the other hand under sense 42 . In fact, the second part of the idiom on the other hand is embedded in the definition and example sentence under on the one hand, which may suggest that one hyperlink will do: ${ }^{10}$ 
You use on the one hand to introduce the first of two contrasting points, facts, or ways of looking at something. It is always followed later by on the other hand or 'on the other'.

On the one hand, if the body doesn't have enough cholesterol, we would not be able to survive. On the other hand, if the body has too much cholesterol, the excess begins to line the arteries.

(COBUILD)

In MEDO, there is also double access to the idiom, from the Phrases section in $\mathrm{ME}$ and the OE panel. Both hyperlinks take the user to the same entry for on the one hand...on the other hand. Here, the duplication is justified, OE featuring as the search panel in MEDO. In contrast, LDOCE and OALD cover this idiom only once. OALD defines the form (on the one hand...) on the other (hand)... in the Idioms box in ME, without any cross-reference. LDOCE hyperlinks it from a separate numbered sense on the other hand, and provides the full form on the one hand...on the other hand as an alternative in brackets.

Other cases of multiple hyperlinks resulting from unnecessary recognition of distinct canonical forms have also been found. In MEDO, there are cross-references to three separate entries hands off, keep your hands off and take/get your hands off, all three of them hyperlinked from the Phrases section (see Figure 12), whereas, for example, in LDOCE there is only one hyperlink to the entry for hands off with the variant form keep your hands off embedded in an example sentence. The definitions in the three hyperlinked entries in MEDO convey the same meaning, but the wording is different (see the extracts below Figure 12). Hence, it is suggested that these multiple cross-references are redundant and should be replaced with one hyperlinked canonical form.

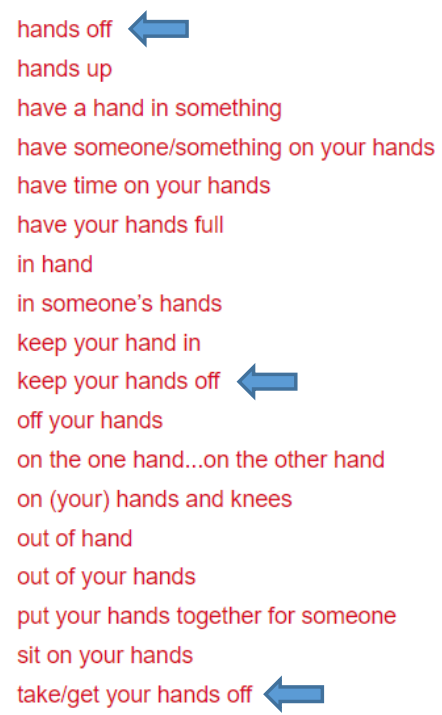

Figure 12: Multiplication of hyperlinks in the Phrases section in MEDO 
hands off

used for telling someone not to touch or take someone or something

keep your hands off

to not touch someone or something

take/get your hands off

to stop touching someone or something

(MEDO)

The duplication or multiplication of entries, however, is not dictionary-specific, since a reverse situation is observed for the idiom give somebody the cold shoulder, with more hyperlinks found in LDOCE than in MEDO. In MEDO the idiom is hyperlinked twice: in the See also section at the bottom of ME, and in the OE search panel, in both cases to the same entry for cold shoulder, which incorporates the phrase get/be given the cold shoulder:

\section{cold shoulder}

PHRASE

get/be given the cold shoulder

to be treated in an unfriendly way by someone you know

(MEDO)

LDOCE, however, unnecessarily multiplies hyperlinks, placing give somebody the cold shoulder among the MWEs grouped at the bottom of ME before the Collocations box, and cold shoulder and (give somebody/get) the cold shoulder in the MR panel. There is one more hyperlinked entry in the MR panel, but it is the same as the one cross-referenced from the MWEs at the bottom of ME. As the dictionary extracts below illustrate, the definitions and most example sentences for the three variant forms are different. Interestingly, the hyperlinked entry for cold shoulder provides a cross-reference to the entry for (give somebody/get) the cold shoulder instead of a definition. The multiplication of cross-references seems redundant, also because a few example sentences overlap, and some under cold shoulder contain the collocate give from the other two variant forms (see the underlined examples and the highlighted collocates). Hence, one canonical form with the first part of the idiom give somebody in brackets would suffice.

give somebody the cold shoulder

to deliberately ignore someone or be unfriendly to them, especially because they have upset or offended you

- After I got the promotion, a few of my co-workers started giving me the cold shoulder.

- So they have given girlfriends the cold shoulder.

- $\quad$ She was sure that at some point she'd given some one the cold shoulder and hurt them badly without noticing.

- Vernon regretted giving Harcourt the cold shoulder; he would have been some one to laugh with. 
(give somebody/get) the cold shoulder

to behave in an unfriendly way towards someone that you know

- So they have given girlfriends the cold shoulder.

- Giving the cold shoulder to his usual tipple, Ian Knight raises his coffee cup to Drinkwise Day.

- She was sure that at some point she'd given some one the cold shoulder and hurt them badly without noticing.

- A declaration of love, or the cold shoulder.

cold shoulder

$\rightarrow$ (give somebody/get) the cold shoulder

- Then from then on, we were treated with an absolute cold shoulder, and no one would speak to us.

- Rachaela had turned on Ruth, not just the habitual cold shoulder, but with a firework of dislike and alienation.

- So they have given girlfriends the cold shoulder.

- She was sure that at some point she'd given some one the cold shoulder and hurt them badly without noticing.

- A declaration of love, or the cold shoulder.

- Banishment was better than this cold shoulder.

(LDOCE)

The analysis shows that the differences between the hyperlinked variant forms can really be of little significance. For instance, lend an ear is hyperlinked twice in the OE search panel in MEDO, the only difference being the presence of the preposition to in brackets in one of the cross-references (see Figure 13).

\author{
lend an ear PHRAsE \\ ear-splitting ADJECTIVE \\ external ear noun \\ cauliflower ear noun \\ play it by ear PHRASE \\ have a tin ear PHRASE \\ bend someone's ear PHRASE \\ cock an/your ear PHRASE \\ have someone's ear PHRASE \\ lend an ear (to) PHRASE
}

Figure 13: Duplication of hyperlinks in the search panel in MEDO 
The definitions, though differently worded, convey the same meaning, and should be merged under one entry. The former entry is also cross-referenced from the Phrases section.

\author{
lend an ear \\ to listen to someone talking about their problems \\ lend an ear (to) \\ to listen to someone, especially someone who is upset \\ Just lend a sympathetic ear while she tells you her problems. \\ (MEDO)
}

Similarly, play something by ear is hyperlinked three times from the OE panel in MEDO, the MWEs having almost identical forms: play it by ear, play something by ear and play (something) by ear. The middle hyperlinked entry on its own would be enough, as it covers both the literal and figurative meanings of the expression (in reverse order). In fact, this is the one also cross-referenced from the Phrases section at the bottom of ME.

\title{
play it by ear
}

to decide what to do as a situation develops rather than planning what you will

do before you start

We don't know how many people are going to come, so we'll play it by ear.

play something by ear

1. to deal with a situation without having a plan, by reacting to things as they happen

2. to play music by hearing and remembering it, not by reading it

play (something) by ear

to perform a piece of music by remembering what it sounds like, without looking at the notes

(MEDO)

Yet another configuration of double access routes is found for the examined MWEs, but its occurrence is rare in the present study. This is double access within ME. The representation of the expression in the hands of somebody/in somebody's hands in LDOCE serves as an example. First, the expression is embedded in an example sentence under sense 3 tagged with the signpost 'control', and then it is hyperlinked under sense 8 (see Figure 14). Semantic distance is unnecessarily created between senses 3 and 8. Double access within $\mathrm{ME}$ can also be observed in the Idioms box in OALD, where two variant forms of the same expression are sometimes defined separately. This has already been discussed in 3.1. 
3 CONTROL [singular, uncountable] control, power, or influence that someone has

4. The president has strengthened the hand of the gun lobby.

4his matter is too important to be left in the hands of (=in the control of) an inexperienced lawyer

4) a manager with a firm hand (=who controls things strictly)

$4 \rightarrow$ get out of hand

$5 \rightarrow$ on the other hand

$6 \rightarrow$ hands off

$7 \rightarrow$ in hand

$8 \rightarrow$ in the hands of somebody/in somebody's hands

Figure 14: Double access routes within ME in LDOCE for in the hands of sb

\section{Item-specific treatment}

In order to find out if there is any item-specific treatment with regard to access routes, hand, shoulder and ear MWEs included in all the five MELDs were selected. The total amounts to 49 shared items, which constitutes $35-49 \%$ of the examined MWEs, depending on the dictionary. Numerous MWEs are covered in four or three of the five MELDs. Leaving the issue of absence of some body part expressions for future research, it was investigated if any MWEs are presented in a similar way.

The study shows that there is a tendency for some MWEs to be defined on the page of the body part headword under one of the first senses. Their top positions in the entry are, obviously, mainly due to the corpus-based frequency. The expression give/lend somebody a hand is one of them, together with its variants, need/want a hand. These forms are provided in example sentences under sense 3 in OALD, sense 4 in CALD, COBUILD and MEDO, and under hyperlinked sense 2 in LDOCE. Additionally, these senses are tagged with the metonymic meaning 'help' as a navigational device guiding the user to the appropriate sense in CALD, MEDO and OALD. A hyperlink is used only in LDOCE, to the entry $a$ hand (see Figure 15). This treatment may mislead the user, who does not see the relevant MWE on the page of the headword, not even as a hyperlink. 


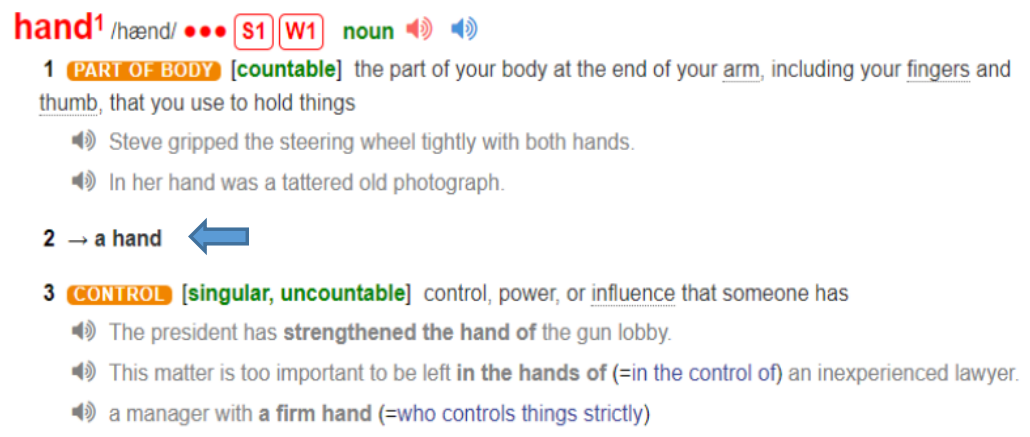

\section{a hand}

help with something - used in the following phrases need/want a hand

4.) Do you need a hand packing?

give/lend (somebody) a hand

4) Can you give me a hand to lift this?

4.) If you get stuck, Denise is always willing to lend a hand.

I could do with a hand/use a hand (=it would be useful to have some help)

4i) We could certainly do with a hand

$\rightarrow$ a helping hand

Figure 15: A hyperlink to the 'help' meaning of hand in LDOCE

Another metonymic extension of the literal hand, 'somebody who does physical work', in most of the examined MELDs tagged with the navigational device 'worker' or 'person', also tends to be defined under one of the first senses in four of the five MELDs: sense 5 in CALD and COBUILD, sense 2 in MEDO and senses 6 and 7 in OALD, sense 7 separately for the 'sailor' meaning. Only in LDOCE it is defined under sense 39, separated from the other definitions by numerous hyperlinks. The relevant compound nouns such as factory hand, farm hand, hired hand, deck hand feature in example sentences, and they are also sometimes hyperlinked from the respective senses (in CALD and OALD). As for MWEs with the other body part names, have an ear for sth is defined under one of the first senses in four out of five MELDs under scrutiny (sense 2 in COBUILD and MEDO, sense 6 in LDOCE and sense 3 in OALD). The expression on sb's shoulders is also ordered at the top in three of the dictionaries: under sense 2 in CALD, sense 3 in COBUILD and hyperlinked sense 7 in LDOCE. However, it is hyperlinked from the Phrases section in MEDO, and defined in the Idioms box in OALD.

The analysis shows that apart from the obvious corpus frequency criterion, MWEs which are less fixed and more modifiable, and hence subject to variations in form tend to be defined at the top of the body part entry. The definition under a given sense provides the general (metonymic) meaning of the body part, and the variant forms of a MWE appear in example sentences. 
Nonetheless, the study proves that the MWEs present in all the 'Big Five' very rarely exhibit item-specific treatment which would manifest itself in common access routes to certain expressions. The same MWE frequently appears in different locations in each of the MELDs, defined or hyperlinked. A case in point is have $a$ hand in sth. It is defined under separate senses in CALD and OALD (senses 6 and 4 respectively), hyperlinked from separate senses in COBUILD and LDOCE (senses 26 and 21 respectively), cross-referenced from the Idioms or Phrases sections in COBUILD and MEDO, and hyperlinked from the search panels in CALD and MEDO. This and similar examples of different treatment of a given expression in the five dictionaries are probably due to the already mentioned lack of clear classifications of MWEs in literature.

No item-specific treatment has also been found with respect to duplication or multiplication of access routes. Here the number of double or multiple access routes from ME (the MWEs being defined, hyperlinked or provided in example sentences) and the search panel was taken into account, not the number of double or multiple hyperlinks within the search panel, as LDOCE does not exhibit the latter form of duplication. In fact, only one item of the 49 shared MWEs receives double access in all the five dictionaries, the prepositional phrase (close/near) at hand. Additionally, 10 MWEs (20\%) demonstrate duplication or multiplication of hyperlinks in four of the five MELDs. Thus, the majority of the expressions have double or multiple access routes merely in three or fewer MELDs. As Figure 16 shows, the proportions of double or multiple access routes to the 49 MWEs in each of the dictionaries correspond to the ones to all the MWEs presented in 3.2.3. Again the duplication or multiplication of access routes is the most frequent in CALD and COBUILD (55\%), and the least frequent in OALD $(27 \%)$, which proves that it is dictionary-specific, not item-specific.

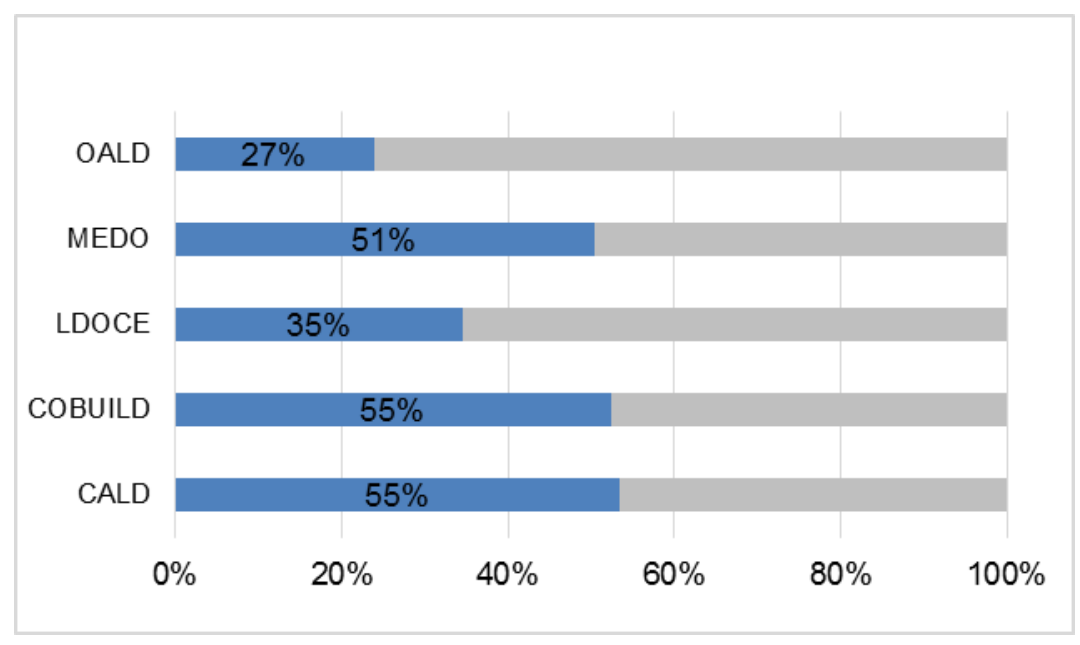

Figure 16: The proportions of double or multiple access routes to the 49 MWEs shared by the 'Big Five' 


\section{Conclusions}

The findings of the study reveal that access routes to body part MWEs are relatively consistent in the MELDs under analysis, and clear preferences have been described for each dictionary. When the dictionaries are compared, it turns out that access routes rarely depend on a specific item. However, some general tendencies in accessing body part MWEs have been observed. It appears that the current practice is to hyperlink MWEs instead of defining them on the page of the headword. The huge majority of the examined body part expressions are hyperlinked to a separate entry. The only exception is OALD, which adopts a reverse approach, defining most of the items in the body part entry, mostly in the Idioms box. Another similarity is locating MWEs in three main positions: separate senses, Idioms or Phrases boxes or sections and search panels, with dictionary-specific distribution.

Duplication or multiplication of access routes within a single body part entry is also observed in all the dictionaries, in some of them to quite a large extent. Double or multiple hyperlinks are found from ME and the search panel or within the search panel itself. The abundance of cross-references is the result of access to aggregated dictionaries and the use of a few slightly differing canonical forms. Double or multiple hyperlinks should not always be seen as something redundant. They seem fine and, in fact, unavoidable, if they come from distinct aggregated dictionaries. They are, however, cases of redundancy and inconsistency if the cross-referenced entries belong to the same dictionary and include different definitions and example sentences, and if the separately hyperlinked MWEs are variants of the same canonical form. In such cases semantic distance between related forms is unnecessarily created. Hyperlinking items both from ME and the search panel is also something self-evident, bearing in mind the role of the latter in helping the user find the target item.

It is hoped that the study shows the need for further research into the area of access routes to MWEs which will incorporate a wider scope of expressions. This might contribute to a more consistent and cognitively oriented representation of MWEs in MELDs.

\section{Endnotes}

1. Due to the search technique now widely applied in e-lexicography known as incremental search or search-as-you-type, users can see the target item among the suggestions that appear in the search box already after typing a few characters. Such pull-down lists with suggested items also include MWEs.

2. See Gouws (2018: 46) for the distinction between access structure and search route/path.

3. For definitions of metaphor and metonymy in cognitive linguistics, see, for example, Lakoff and Johnson ([1980] 2003) and Ungerer and Schmid ([1996] 2006).

4. These are free online versions, where access codes are not required. 
5. American versions of the dictionaries are excluded from the study because they are just American counterparts of the same dictionaries.

6. In LDOCE entries from Longman Business Dictionary are presented at the bottom of the page, in MEDO no dictionaries are aggregated apart from the American version, and OALD at the bottom of the page provides hyperlinks to the respective entries, not distinct MWEs, from Oxford Learner's Dictionary of Academic English available with an access code, and under certain senses offers hyperlinks to Oxford Collocations Dictionary, also accessed with a purchase code.

7. Before February 2020, the search panel in MEDO was named Related words.

8. In this paper, the term cross-reference is used interchangeably with hyperlink, which is its electronic form.

9. The compounds glue ear and hard shoulder do not belong to the examined MWEs, as they are based on metaphor rather than metonymy.

10. In the entries cited in the paper, exact typography has not been replicated and information redundant for the study has been omitted.

\section{References}

\section{Dictionaries}

Cambridge Advanced Learner's Dictionary. (CALD) Accessed on 10 February 2020: http://www.dictionary.cambridge.org

COBUILD Advanced English Dictionary. (COBUILD) Accessed on 10 February 2020: http://www.collinsdictionary.com

Longman Dictionary of Contemporary English. (LDOCE) Accessed on 10 February 2020: http://www.ldoceonline.com

Macmillan English Dictionary Online. (MEDO) Accessed on 10 February 2020: http://www.macmillandictionary.com

Oxford Advanced Learner's Dictionary. (OALD) Accessed on 10 February 2020: http://www.oxfordlearnersdictionaries.com

\section{Other literature}

Adamska-Sałaciak, A. 2008. Prepositions in Dictionaries for Foreign Learners: A Cognitive Linguistic Look. Bernal, E. and J. DeCesaris (Eds.). 2008. Proceedings of the XIII EURALEX International Congress, EURALEX 2008, Barcelona, 15-19 July 2008: 1477-1485. Barcelona: Universitat Pompeu Fabra.

Atkins, B.T.S. and M. Rundell. 2008. The Oxford Guide to Practical Lexicography. Oxford: Oxford University Press.

Boers, F. and S. Lindstromberg. 2006. Cognitive Linguistic Applications in Second or Foreign Language Instruction: Rationale, Proposals, and Evaluation. Kristiansen, G., M. Achard, R. Dirven and F.J. Ruiz de Mendoza Ibáñez (Eds.). 2006. Cognitive Linguistics: Current Applications and Future Perspectives: 305-355. Berlin/New York: Mouton de Gruyter. 
Cowie, A.P. (Ed.). 1998. Phraseology: Theory, Analysis, and Applications. Oxford: Clarendon Press.

Dobrovol'skij, D. and E. Piirainen. 2005. Figurative Language: Cross-Cultural and Cross-Linguistic Perspectives. Amsterdam: Elsevier.

Fellbaum, C. 2007. Argument Selection and Alternations in VP Idioms. Fellbaum, C. (Ed.). 2007. Idioms and Collocations: Corpus-based Linguistic and Lexicographic Studies: 188-202. London: Continuum.

Geeraerts, D. 2002. The Interaction of Metaphor and Metonymy in Composite Expressions. Dirven, R. and R. Pörings (Eds.). 2002. Metaphor and Metonymy in Comparison and Contrast: 435-465. Berlin: Mouton de Gruyter.

Geeraerts, D. 2007. Lexicography. Geeraerts, D. and H. Cuyckens (Eds.). 2007. The Oxford Handbook of Cognitive Linguistics: 1160-1174. Oxford: Oxford University Press.

Gibbs, R. 1993. Why Idioms are not Dead Metaphors. Cacciari, C. and P. Tabossi (Eds.). 1993. Idioms: Processing, Structure, and Interpretation: 57-77. Hillsdale, NJ: Lawrence Erlbaum Associates.

Goossens, L. [1990] 2002. Metaphtonymy: The Interaction of Metaphor and Metonymy in Expressions for Linguistic Action. Dirven, R. and R. Pörings (Eds.). 2002. Metaphor and Metonymy in Comparison and Contrast: 349-377. Berlin: Mouton de Gruyter.

Gouws, R. H. 2018. Dictionaries and Access. Fuertes-Olivera, P.A. (Ed.). 2018. The Routledge Handbook of Lexicography: 43-58. London/New York: Routledge.

Hanks, P. 2013. Lexical Analysis: Norms and Exploitations. Cambridge, Massachusetts: The MIT press.

Kövecses, Z. and S. Csábi. 2014. Lexicography and Cognitive Linguistics. Revista Española de Lingüística Aplicada/Spanish Journal of Applied Linguistics 27(1): 118-139.

Lakoff, G. and M. Johnson. [1980] 2003. Metaphors We Live By. Chicago/London: University of Chicago Press.

Langlotz, A. 2006. Idiomatic Creativity: A Cognitive-Linguistic Model of Idiom-Representation and IdiomVariation in English. Human Cognitive Processing 17. Amsterdam/Philadelphia: John Benjamins.

Lew, R. 2012. How can We Make Electronic Dictionaries More Effective? Granger, S. and M. Paquot (Eds.). 2012. Electronic Lexicography: 343-361. Oxford: Oxford University Press.

Moon, R. 1998. Fixed Expressions and Idioms in English: A Corpus-based Approach. Oxford: Oxford Clarendon Press.

Moon, R. 2004. On Specifying Metaphor: An Idea and its Implementation. International Journal of Lexicography 17(2): 195-222.

Oppentocht, L. and R. Schutz. 2003. Developments in Electronic Dictionary Design. Van Sterkenburg, P. (Ed.). 2003. A Practical Guide to Lexicography: 215-227. Terminology and Lexicography Research and Practice 6. Amsterdam/Philadelphia: John Benjamins.

Ostermann, C. 2015. Cognitive Lexicography: A New Approach to Lexicography Making Use of Cognitive Semantics. Lexicographica. Series Maior 149. Berlin: De Gruyter.

Palmer, H.E. 1933. Second Interim Report on English Collocations. Tokyo: Kaitakusha.

Sinclair, J. (Ed.). 1987. Looking Up: An Account of the COBUILD Project in Lexical Computing. London/Glasgow: Collins.

Sinclair, J. (Ed.). 1991. Corpus, Concordance, Collocation. Oxford: Oxford University Press.

Stathi, K. 2007. A Corpus-based Analysis of Adjectival Modification in German Idioms. Fellbaum, C. (Ed.). 2007. Idioms and Collocations: Corpus-based Linguistic and Lexicographic Studies: 81-108. London: Continuum. 
http://lexikos.journals.ac.za; https://doi.org/10.5788/30-1-1602

608

Sylwia Wojciechowska

Ungerer, F. and H.-J. Schmid. [1996] 2006. An Introduction to Cognitive Linguistics. London/New York: Longman.

Van der Meer, G. 1999. Metaphors and Dictionaries: The Morass of Meaning, or How to Get Two Ideas for One. International Journal of Lexicography 12(3): 195-208. 